Georgia State University

ScholarWorks @ Georgia State University

5-7-2016

\title{
Psychological Outcomes of Perpetrating Sexual Violence: A Qualitative Analysis
}

Carolyn Brennan

Follow this and additional works at: https://scholarworks.gsu.edu/psych_theses

\section{Recommended Citation}

Brennan, Carolyn, "Psychological Outcomes of Perpetrating Sexual Violence: A Qualitative Analysis." Thesis, Georgia State University, 2016. doi: https://doi.org/10.57709/8457441

This Thesis is brought to you for free and open access by the Department of Psychology at ScholarWorks @ Georgia State University. It has been accepted for inclusion in Psychology Theses by an authorized administrator of ScholarWorks @ Georgia State University. For more information, please contact scholarworks@gsu.edu. 


\title{
PSYCHOLOGICAL OUTCOMES OF PERPETRATING SEXUAL VIOLENCE:
}

\section{A QUALITATIVE ANALYSIS}

by

\section{CAROLYN L. BRENNAN}

Under the Direction of Kevin Swartout, $\mathrm{PhD}$

\begin{abstract}
Despite the vast body of research on outcomes of sexual violence victimization, little is known about the psychological outcomes of sexual violence perpetration. This omission is significant, due to the fact that preventing recidivism may depend on treatment of identified perpetrators. The purpose of the current thesis is to examine the psychological responses to perpetrating sexual violence with a qualitative analysis of first-hand accounts of sexual violence perpetration, obtained from anonymous posts on Reddit.com. The analysis revealed four primary emotional outcomes to perpetrating sexual violence: shame, remorse, depression, and anger. The four themes appeared independently and were associated with different contextual themes. Remorse, unlike the other themes, co-occurred with reports of self-growth, indicating that remorse may be a more adaptive outcome. The results also indicated that the social context played an important role in perpetrator outcomes. These findings have important clinical implications for the treatment of perpetrators.

INDEX WORDS: sexual assault, perpetrator psychology, rape
\end{abstract}




\section{PSYCHOLOGICAL OUTCOMES OF PERPETRATING SEXUAL VIOLENCE: A QUALITATIVE ANALYSIS}

by

CAROLYN L. BRENNAN

A Thesis Submitted in Partial Fulfillment of the Requirements for the Degree of Master of Arts

in the College of Arts and Sciences

Georgia State University 
Copyright by Carolyn Louise Brennan 2016 


\section{PSYCHOLOGICAL OUTCOMES OF PERPETRATING SEXUAL VIOLENCE: A QUALITATIVE ANALYSIS}

by

Carolyn L. Brennan

Committee Chair: Kevin Swartout

Committee: Sarah Cook

Dominic Parrott

Electronic Version Approved:

Office of Graduate Studies

College of Arts and Sciences

Georgia State University

May 2016 


\section{DEDICATION}

I would like to thank all of my friends and family for their ongoing support that helped me to achieve this milestone. Above all, I owe this achievement to Marian Schuman for always believing in me. 


\section{ACKNOWLEDGEMENTS}

I would like to thank my committee chair, Kevin Swartout, for his help and guidance in preparing this document, as well as my other committee members, Sarah Cook and Dominic Parrott. I would also like to thank Nikita Rodrigues for her help with analyzing the data. 


\section{TABLE OF CONTENTS}

ACKNOWLEDGEMENTS $\mathbf{V}$

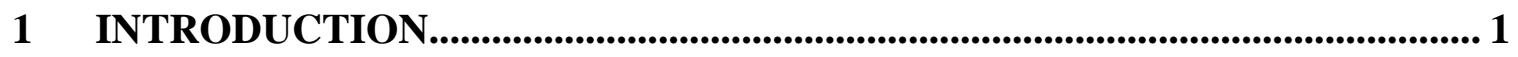

1.1 Models of Sexual Violence Re-Perpetration ................................................ 2

1.1.1 Individual-level models of sexual violence .................................................. 2

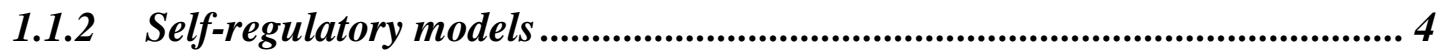

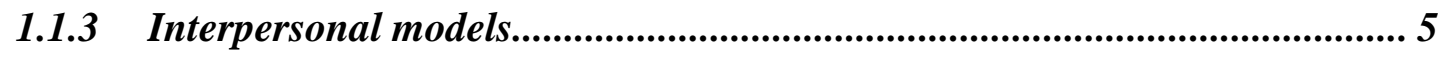

1.2 Outcomes of Other Forms of Violent Perpetration .................................. 6

1.3 The Current Study ............................................................................................... 9

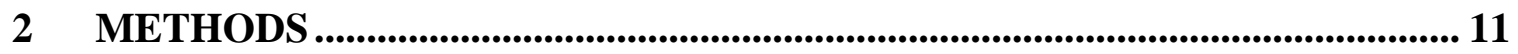

2.1 Data Collection ..................................................................................... 11

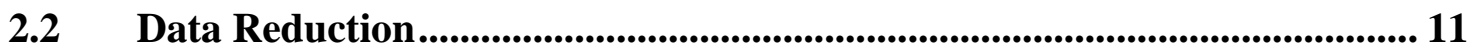

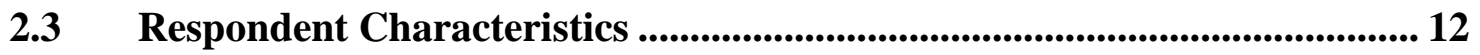

$2.4 \quad$ Response Bias .......................................................................................... 12

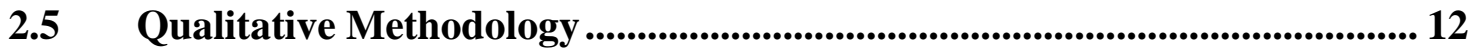

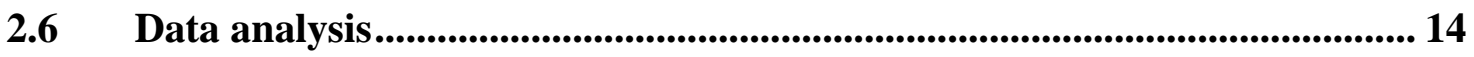

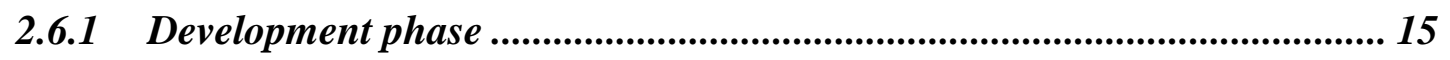

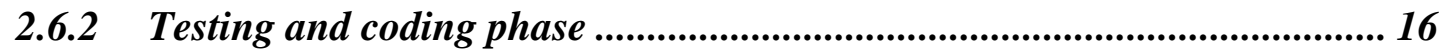

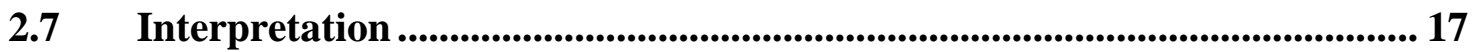

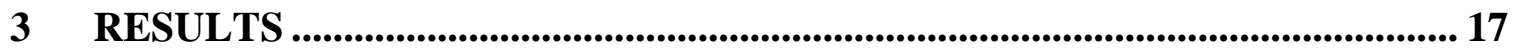




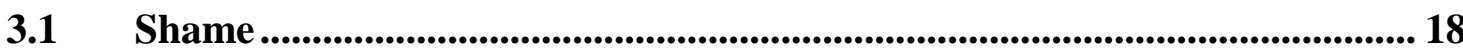

3.1.1 Shame, perpetrator alcohol use, and consent confusion............................. 21

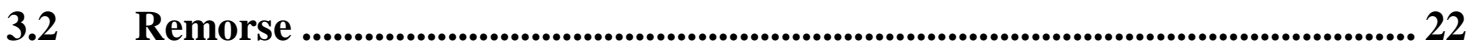

3.2.1 Remorse and self-growth .......................................................................... 23

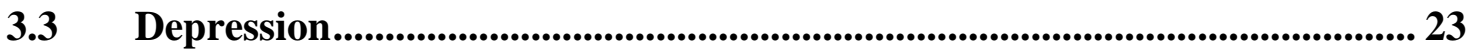

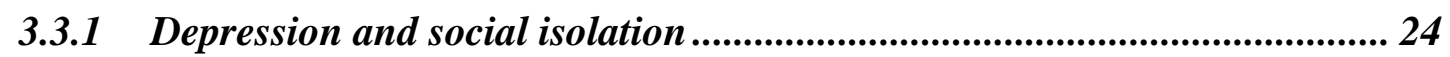

$3.4 \quad$ Anger toward the victim......................................................................................... 26

3.4.1 Anger and hostility toward women ................................................................ 27

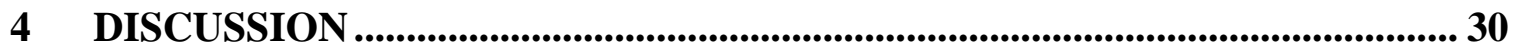

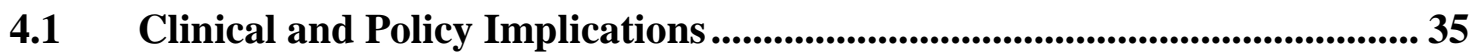

4.2 Limitations and Future Directions ......................................................................... 36

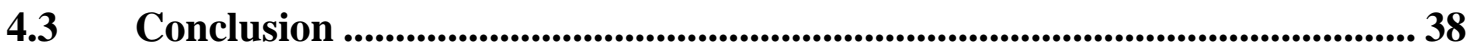

REFERENCES............................................................................................................................. 40

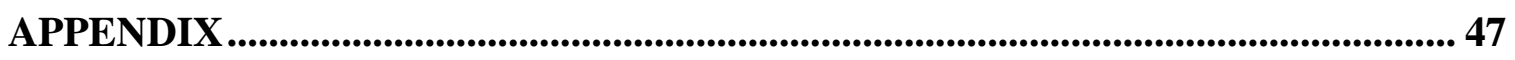

Figure 1. The Cyclical Model of Shame and Sexual Violence....................................... 47

Figure 2. A narrative with shame broken down into the elements of the Cyclical Model of Shame and Sexual Violence..................................................................................................... 48

Figure 3. The four primary outcomes of perpetrating sexual violence, the cooccurring themes, and the social significance of these themes. 
Figure 4. The relationship between social isolation, the label "rape," and depressed affect. 


\section{INTRODUCTION}

Sexual violence, defined by the Centers for Disease Control and Prevention (2014) as any sexual activity with a person who is unable or unwilling to consent, occurs at overwhelming rates. Moreover, a significant proportion of sexually violent acts are perpetrated by repeat offenders; a nationally representative survey found that more than half of all acts of sexual violence committed in a 12-month period are instances of repeat perpetration (Koss, Gidycz, \& Wisniewski, 1987). Thus, intervening among men who have perpetrated sexual violence in the past could significantly reduce rates of sexual violence. Yet in order to intervene among this group, we must first understand the psychological responses to perpetration, as this knowledge will help inform the motivation to perpetrate again. The purpose of the current study is to examine perpetrators' responses to committing acts of sexual violence to foster a new approach to sexual violence intervention.

Our limited knowledge of the psychological outcomes among non-adjudicated perpetrators of sexual violence is in part due to the fact that this is a difficult population to identify, despite findings that approximately 25\%-30\% of men report perpetrating some form of sexual violence (Koss et al., 1987; Thompson, Swartout, \& Koss, 2013). Many perpetrators may be reluctant to disclose the details of their aggressive acts due to the stigmatized and illegal nature of sexual violence. Nevertheless, given the high rates of repeat offenses among men who perpetrate sexual violence (Koss et al., 1987; White \& Smith; 2004), the lack of atten,tion to affective and cognitive responses to perpetration results in an incomplete picture of the psychological processes that give rise to acts of sexual violence. 
Although research has explored the outcomes of sexual violence for the victim, little is known about the psychological outcomes of perpetrating sexual violence. To the extent that studies have examined perpetrators' affective or interpersonal functioning, this has been limited to risk factors that are believed to exist prior to an initial offense. Certain theoretical models of repeat sexual offending have incorporated perpetrators' affective reactions to the assault (Marshall, Marshall, Serran \& O’Brien, 2009; Wolf, 1989), yet the psychological outcomes of perpetrating sexual violence have not been empirically studied. This omission hinders the development of appropriate interventions to treat men who perpetrate sexual violence. In the present study, I address this gap in the literature by conducting a qualitative analysis of first-hand accounts of sexual violence perpetration, specifically analyzing men's narratives of sexual perpetration against women, as the vast majority of sexually violent acts are cases of male-tofemale violence (Breiding, Basile, Walters, Chen, \& Merrick, 2014).

\subsection{Models of Sexual Violence Re-Perpetration}

\subsubsection{Individual-level models of sexual violence}

Despite the dearth of empirical evidence on psychological outcomes of sexual violence perpetration, some theoretical models of sexual violence make predictions regarding men's likely psychological responses to perpetration (Kivisto, Kivisto, Moore \& Rhatigans, 2011; Marshall et al., 2009; Ward, Hudson \& Keenan, 1998; Wolf, 1989). Figure 1 presents what I have termed the Cyclical Model of Shame and Sexual Violence, a synthesized, theoretical model of psychological responses to perpetration as they relate to a cycle of repeat perpetration. The model was created to visually depict common themes across theories of sexual violence re-perpetration and to accommodate non-overlapping elements of these theories into one cohesive framework. 
In his model of sexual offense, Wolf (1989) outlined how cognitive and affective reactions to an assault can motivate a perpetrator to re-offend. According to this model, a perpetrator's negative self-image motivates him to commit the initial offense. The perpetrator is unduly focused on his needs and goals, and he compensates for his negative self-image with fantasies of control. Guilt surrounding these fantasies, and the offense itself, is reduced with cognitive distortions such as justification and minimization. This stage constitutes an example of motivated cognition, whereby one's goals (e.g., preservation of one's self-image) can influence the interpretation of an event (Showers \& Cantor, 1985). In this instance, the perpetrator is motivated to interpret the offense as being justified or causing only minimal harm to the victim to protect his self-image. According to Wolf's model, any guilt or shame that arises following the assault may further lower the perpetrator's self-esteem and perpetuate the cycle of sexual offending. Additionally, the cognitive distortions intended to protect the perpetrator's self-image may also contribute to re-perpetration, as denial of responsibility prevents him from changing his behaviors; see pathways 2 and 4. Therefore, according to Wolf's model, cognitive and affective reactions to perpetration are influenced by the perpetrator's goals and motivate him to re-offend.

Other theories hypothesize that cognitive and affective reactions to perpetrating sexual violence can include shame, cognitive distortions, and lack of empathy toward the victim, which may all be functionally related. Marshall et al. (2009) argued that shame, which is characterized in part by excessive focus on the self, can result in a lack of empathy for the victim (pathway 3). Since empathy has been found to be a protective factor against sexual violence (Abbey, Parkhill, Clinton-Sherrod, \& Zawacki, 2007; Wheeler, George, \& Dahl, 2002), reduced empathy may increase the likelihood of reoffending (pathway 5). Additionally, cognitive distortions, such as denying responsibility, blaming the victim or context, or minimizing any harm done to the 
victim, may protect against a negative self-image following the assault. Victim blame and other cognitive distortions may reinforce attitudes such as hostility toward women that are predictive of sexual violence (Malamuth et al., 1991; pathway 4). Furthermore, past research has found that shame indirectly predicts aggression through externalizing blame (Stuewig, Tagney, Heigel, Harty, \& McCloskey, 2010).

\subsubsection{Self-regulatory models}

Self-regulatory models of sexual violence re-perpetration rest on the assumption that an internal conflict exists between the perpetrator's ideal behavior and his actual sexually violent behavior. As internal goals are connected to our emotions, such that failing to achieve our goals is associated with negative emotions (Carver \& Scheier, 1990), the perpetrator whose goal is to not exhibit sexually violent behavior will react negatively to his behavior. Ward et al. (1998) argued that perpetrators can be differentiated by their motivations and capacity to correct sexual violence, and predictions can be made about how each group will react to the assault. They argued for the existence of three self-regulatory classifications: intact regulation, underregulation, and misregulation. Intact regulation describes the perpetrators who do not selfregulate coercive sexual behaviors because they do not interpret this behavior as problematic. This group will most likely not have a negative reaction following the assault. In contrast, the remaining two groups are unable to correct their behavior due to insufficient cognitive resources (underregulation), or through maladaptive strategies, such as thought suppression or substance

use (misregulation). The underregulation and misregulation groups may have a negative reaction to their sexually violent behavior. Therefore, like the models of repeat perpetration outlined above, self-regulatory models also predict that some perpetrators will have negative emotional responses to their violent behavior. 


\subsubsection{Interpersonal models}

The social-ecological framework emphasizes the multiple levels of influence that contribute to gender-based violence (Bronfenbrenner, 1977; Heise, 1998). In addition to individual level risk factors, there is evidence that sexually coercive behaviors are influenced by exosystem factors, such as associating with sexually aggressive peers (DeKeseredy \& Kelly, 1995; Heise, 1998; Jacques-Tiura, Abbey, Wegner, Pierce, Pegram, \& Woerner, 2015; Swartout, 2013), and macrosystem factors, such as culturally bound gender role norms (Heise, 1998; Malamuth et al., 1991).

The model of sexual violence perpetration proposed by Malamuth et al. (1991) is based within the ecological framework. The model outlines two pathways to sexual violence: a hostile masculinity pathway characterized by the presence of attitudes that are hostile and accepting of violence toward women, and an impersonal sex pathway characterized by sexual promiscuity with low emotional attachment. Although both pathways are defined in terms of individual-level characteristics, such as attitudes and sexual behaviors, the authors reasoned that both routes are influenced by adolescent delinquency. Adolescent delinquency, in turn, can be traced back to an association with delinquent peers and a hostile home environment.

In an extension of Malamuth et al.’s (1991) confluence model of sexual aggression, Swartout (2013) found that individual attitudes supportive of violence against women and hostile masculinity are influenced by perceived peer attitudes and peer network density. Specifically, men in tightly knit peer groups that are less accepting of sexual violence report less hostile masculinity. Jacques-Tiura et al. (2015) found that men who perceived pressure from peers to engage in sexual activity "by any means," and whose peers spoke about women in objectifying terms, were more likelihood to perpetrate sexual violence. Likewise, DeKeseredy $(1988 ; 1990)$ 
argued that social integration into a group with abusive male peers increases the likelihood of perpetrating violence against one's partner. Furthermore, DeKeseredy $(1988 ; 1990)$ asserted that aggressive male peers provide informational support in the aftermath of an act of violence against a partner. Informational support provides a new interpretive frame for the assault, such as placing the blame on the victim. Silence from peers can also serve as informational support because it can be interpreted as tacit approval (DeKeseredy, 1990). Informational support helps to justify and legitimate the abusive behavior, thereby protecting the aggressor against a negative affective response to his behavior.

Taken together, the interpersonal models underscore the importance of peer attitudes and peer network structure in predicting individual attitudes that give rise to sexual violence. Taken one step further, it can be argued that peer perceptions also influence how the perpetrator makes meaning out of his actions. DeKeseredy's (1990) formulation of informational support suggests that the perpetrator's emotional response is likely influenced by his peers' attempts to provide a more favorable interpretive lens for the assault. The current study may help inform whether the social context, such as the perpetrator's relationship to the victim, or peer approval or disapproval of sexual violence, plays a role in the self-reported psychological responses to sexual violence perpetration.

\subsection{Outcomes of Other Forms of Violent Perpetration}

Although more research is necessary on the outcomes of perpetrating sexual violence, research has recently uncovered possible negative effects of violent perpetration, more broadly defined. Most of this research has centered on violence perpetrated in combat; however, there is also a literature on offense-related traumatization for convicted violent offenders. Sexual violence and physical violence perpetration are not perfectly analogous due to potential variation 
in motivations, relevant predictors, and interpersonal consequences. Nonetheless, research on negative psychological responses in the wake of physical violence perpetration can shed light on how perpetrators of sexual violence react to assaulting another human being.

In a sample of 80 men convicted of homicide, Pollock (1999) found that $52 \%$ met criteria for a posttraumatic stress disorder (PTSD) diagnosis. In particular, when the homicide was a case of reactive violence rather than instrumental violence, the relationship between the offense and PTSD was stronger. Evans, Ehlers, Mezey, and Clark (2007) also found offense related PTSD among a sample of violent offenders, albeit to a less startling degree. In this study $45.7 \%$ of participants convicted for murder or inflicting serious injury had intrusive memories relating to the assault, and 5.7\% met criteria for a PTSD diagnosis with the assault perpetration as the precipitating event. Offenders who suffered from intrusive memories were less likely to endorse antisocial beliefs prior to the offense and were more likely to report remorse. They were also more likely to hold a negative self-image and to endorse the belief that they had permanently changed for the worse.

Similar to research on offense related traumatization in incarcerated samples, studies examining the impact of killing in combat have found negative psychological outcomes, including posttraumatic stress symptoms, depression, and suicidal ideation (Hundt \& Holohan, 2012; Maguen et al., 2012; Maguen et al., 2009; Van Winkle \& Safer, 2011). Additionally, killing experiences and negative views of the self among veterans have been found to predict future violence perpetration outside the context of combat (Hundt \& Holohan, 2012; Van Winkle \& Safer, 2011). Although one could argue that convicted violent offenders suffer negative psychological consequences, in part due to incarceration and other social or legal ramifications, 
the findings on outcomes of perpetrating violence in combat suggests that perpetration in itself is potentially traumatic.

Van Winkle and Safer (2011) compared the relative effects of witnessing combat trauma and killing in combat on PTSD symptoms and subsequent domestic violence. They found that killing experiences were predictive of PTSD symptoms even when controlling for witnessing death or injuries of fellow combatants. Furthermore, spouses' reports of domestic violence were associated with killing in combat, but not witnessing death or injury. Likewise, Maguen et al. (2009) found self-reports of killing among combat veterans to be a significant predictor of both PTSD symptoms and violent behavior. Additionally, their results indicated that veterans who reported killing women, children, or elderly people showed more signs of mental health symptomatology and violent behavior compared to veterans who killed young male civilians or enemy combatants. The increased severity of mental health symptomatology may be associated with the increased stigma attached to harming women, children, or elderly people, as they are often considered to be more defenseless. Support for this reasoning comes from a study by Hundt and Holohan (2012) that found that higher scores on a measure of shame was the strongest predictor of intimate partner violence (IPV) in veterans. PTSD symptoms and depression also predicted IPV in this sample, yet to a lesser degree.

Despite the obvious differences between homicide and sexual violence perpetration, both experiences are highly stigmatized and perpetrators of both types of violence may fear judgment by others. Moreover, even socially sanctioned violence perpetration, such as in the context of combat, can give rise to negative psychological consequences. Taken together, this indicates that sexual violence, which can lead to severe psychological and physical consequences for the victim, may also produce negative psychological consequences in the aggressor. 
Additionally, the above studies indicate a relationship between past violence perpetration, psychological distress, and further violent behavior. It has been argued that the negative selfappraisal that arises out of perpetrating physical violence (Evans et al., 2007), can in turn lead to alienation and a difficulty feeling empathy (Van Vliet, 2010). One may attempt to bolster a sense of self-worth through actions such as violence that denigrate or belittle others (Van Vliet, 2010). This conceptualization of a cycle of violence perpetration is in line with the Cyclical Model of Shame and Sexual Violence discussed in the previous section. As depicted in Figure 1, negative psychological outcomes of sexual violence perpetration may contribute to repeat perpetration. However, more empirical evidence is needed on the psychological effects of perpetrating sexual violence and how they may relate to re-perpetration.

\subsection{The Current Study}

The current study is a qualitative analysis examining the self- reported affective reactions (e.g., shame, guilt, anger, and sadness) to perpetrating sexual violence in first-hand narratives. The narratives were obtained from an anonymous online community (Reddit.com) in response to a post that asked about sexual violence perpetration experiences. Within two days of the original posting, approximately 12,000 comments and responses to these comments were posted, including several first-hand accounts from self-identified perpetrators. These narratives provide insight into an untapped area of research: the psychological outcomes of perpetrating sexual violence.

In this analysis, I examine the self-reported psychological outcomes of perpetration and the contextual details described in the narratives, with particular attention to the social context. Given that cultural norms and peer beliefs influence men's attitudes regarding sexual violence (DeKeseredy, 1988; DeKeseredy, 1990; Jacques-Tiura et al., 2015; Malamuth, Sockloskie, Koss, 
\& Tanaka, 1991; Swartout, 2013), it stands to reason that these social factors also contribute to a perpetrator's interpretation of his past aggressive behavior.

The current qualitative analysis addresses whether the perpetrators' narratives include reactions to the assault that are in line with the models of sexual re-perpetration outlined above. Although qualitative analyses cannot determine which theory most accurately predicts psychological responses to sexual violence perpetration, this study could lay the groundwork for developing hypotheses to test conflicting models. Moreover, as many researchers have argued for the existence of multiple etiological pathways toward sexual offending (Hall \& Hirschman, 1991; Knight \& Sims-Knight, 2004; Malamuth et al., 1991 Marshall \& Barbaree, 1990; Ward et al., 1998), one might expect multiple types of responses to sexual violence. If the qualitative analysis uncovers multiple affective reactions to the assault, this could be informative in developing interventions that target perpetrators.

Because the current study takes an inductive approach to analyzing the data (Creswell, 2007), specific hypotheses are not outlined at this time. However, the following two, general research questions have been developed a priori: 1) how do respondents describe their psychological state in the aftermath of perpetrating sexual violence? 2) How do the respondents describe the contextual factors that precede or co-occur with this psychological state? Based upon research on outcomes of perpetrating physical violence and the theoretical models of repeat sexual violence, I expect that several narratives will include reports of negative affective responses to perpetrating sexual violence. Furthermore, the evidence that perceived peer attitudes are important in predicting individual rape supportive attitudes suggests, in the aftermath of a sexually violent act, the perpetrator's perception of his peers' reactions will influence his own reaction. It is hoped that this study will lay the groundwork for research on perpetrators' 
experiences in order to create more productive interventions to treat men who perpetrate sexual violence and to help prevent recidivism.

\section{METHODS}

\subsection{Data Collection}

Approval was granted by the local Institutional Review Board to retrieve the posts made on Reddit.com in response to the following question posted on July 26, 2012: "Reddit's had a few threads about sexual assault victims, but are there any redditors from the other side of the story? What were your motivations? Do you regret it?" The data collected were publically available and posts were not linked with any identifiable information.

\subsection{Data Reduction}

The research team retrieved 12,000 comments that were posted within the first two days after the question appeared on Reddit. According to the Reddit sorting algorithm, the more popular posts, determined by reader votes, appear first. For feasibility, the data were first limited to the 779 posts that appeared on the first page and were written within the first two days of the initial prompt. The top posts were generally of a higher quality, providing greater detail in the narratives. Next, the data were further limited by excluding narratives that described victimization, second-hand accounts of perpetration, or miscellaneous comments $(n=666)$. The responses were further narrowed down to include only narratives of male-to-female sexual violence, to contribute to the extant literature on male-to-female aggression. Finally, narratives that included sexual abuse of a child or family member were excluded from the analysis because they are beyond the scope of the current research. The number of narratives remaining was 75 . 


\subsection{Respondent Characteristics}

Due to the nature of Reddit, which is an anonymous online community, it is not possible to assess the demographics of the respondents. Reddit.com receives over 24 million visitors each month. One survey found that Reddit users are primarily men between the ages of 18 and 39 (Duggan \& Smith, 2013), and this may reflect the demographics of the respondents whose posts were analyzed in the current study. Taken together, this may indicate the respondents whose narratives were analyzed in the current study represent a more diverse population compared to samples of undergraduate students or prison samples, who typically participate in sexual violence research.

\subsection{Response Bias}

As with all self-report data, there is a risk of inaccurate reporting, often in the form of participants not being truthful about their behaviors, experiences, thoughts, feelings, or attitudes. However, due to the anonymity of the online forum, it is believed that these data were more accurate compared to self-reports completed in a laboratory setting or in an interview format (Joinson, 1999). Whereas respondents may be motivated to appear in a favorable light when there is some level of contact with a researcher, the total anonymity of the posts collected from Reddit.com was likely to have positively influenced participants' candidness.

\subsection{Qualitative Methodology}

The current study is a qualitative text analysis (Kuckartz, 2014) with elements of phenomenological design (Creswell, 2007; Willig, 2012) and discursive analysis (Willig, 1999; Willig, 2012). Qualitative text analysis does not assume an interaction between the researchers and the respondents. This is an appropriate approach for the current study, given the data were 
gathered from an anonymous online public forum, and respondents were not influenced by the researchers.

Phenomenological analysis is a method of qualitative inquiry employed to understand a particular experience. The guiding research question of the current study, examining the experiences of perpetrators in the aftermath of the assault, fits within the framework of a phenomenological design. However, the current study diverges from traditional phenomenological designs in several important ways. In phenomenological analysis, the researcher typically gathers data from a small group of people (around 5-25 participants; Creswell, 2007) who have experienced the phenomenon of interest. Additionally, phenomenological analysis aims to acquire an in-depth understanding of the experience, highlighting the commonalities across cases, with little attention to why a particular individual experienced the phenomenon in that way (Willig, 2012). In contrast, the data for the current study included over 60 narratives, many of which were relatively brief (approximately 1 paragraph). Moreover, I examined both commonalities and variations in the experience of sexual violence perpetrators following the assault, as well as the factors that may have contributed to perpetrators' experiences.

Discursive analysis rests on the premise that language is performative (Emerson \& Frosh, 2004; Willig, 1999). Whereas a phenomenological design focuses on people's experiences, discursive analysis focuses on how these experiences are communicated (Emerson \& Frosh, 2004; Willig, 2012). This entails a critical examination of the choice of language to convey an idea that could be told in a different way, or the decision to include certain details peripheral to the event. The data analyzed for the current study came from people who freely elected to post intimate, stigmatized, and incriminating details of their personal lives in the public domain. One 
must ask what the respondents were trying to accomplish through communicating their stories, and therefore the construction of the narratives warrants attention.

\subsection{Data analysis}

Kuckartz (2014) outlined several stages for qualitative text analysis that guided the analysis for the current study. The qualitative analytic stages include the development phase, the test phase, and the coding phase. These stages are not necessarily discrete steps, but are frequently recursive. Analyses were conducted using ATLAS.ti version 7 qualitative data analysis software. Due to the brevity of each response, I analyzed each post as a single text segment and applied the inductively developed codes to the entire text segment for each post. The stages of analysis for the current study are outlined below.

In line with a phenomenological research design, the focus in coding the data was to provide a textural description and a structural description of psychological responses to perpetrating sexual violence (Creswell, 2007). The textural description paints a picture of what the respondents experienced. To this end, we categorized data specifically related to the experience of a self-identified sexual violence perpetrator following the assault. The structural description provides information on contextual details that are relevant to the phenomenon of interest. In the current study, these were factors described in the narratives that may have influenced the respondents' experiences in the aftermath of sexual violence perpetration, with particular attention to the social context. The contextual themes coded in the current analysis, including the social context, were not intended to relay information on some objective reality, but rather indicated the respondents' subjective experiences. In line with discursive analysis, the current analysis not only looked at the experiences of perpetrators, but also the way in which 
their narratives were constructed. With discursive analysis, the elusive task of obtaining a "true" analysis of the respondents' inner experiences does not invalidate the interpretation.

\subsubsection{Development phase}

The development phase is the initial identification of themes and development of codes. Although the research question was developed prior to analysis, the analysis itself was contentdriven (Creswell, 2007). That is, the researchers identified themes that emerged from the narratives of sexual violence perpetration that shed light on the experience of perpetrators following the assault. Themes and codes were not determined a priori, but rather were derived from the text itself. The analytic lens chosen for the current study, a combination of phenomenological and discursive analysis, focused the attention to specific elements of the narratives. However, as indicated by Kuckartz (2014), narrowing the focus of potential themes does not negatively affect the validity of the study as long as respondents were allowed to write freely and the codes are in line with the data. In order to further diminish the potential subjective bias in the identification of salient themes, a team of two researchers independently read through a portion of the narratives (25\%) and developed a list of themes to be used as codes. Potential codes and definitions of the codes were determined once consensus had been reached between the researchers.

The data were first read through for general impressions, followed by a closer reading of the meanings in each statement - the descriptive stage (Willig, 2012). At each stage of analysis, codes became successively more abstract in order to eventually identify commonalities across narratives (Creswell, 2007). Salient ideas that emerged in a single narrative were then phrased in more general terms to accommodate similar ideas that occurred in a separate narrative, thereby identifying common patterns across narratives. For instance, if one respondent wrote about binge 
drinking and another wrote about consuming illegal drugs, these ideas were abstracted and combined under the code of "substance abuse." This process is also referred to as "factoring" in the guidelines for analyzing qualitative data laid out by Miles, Huberman, and Saldaña (2014).

In line with a phenomenological research design, the focus in coding the data was to provide a textural description and a structural description of psychological responses to perpetrating sexual violence (Creswell, 2007). The textural description paints a picture of what the respondents experienced. To this end, we categorized data specifically related to the experience of a self-identified sexual violence perpetrator following the assault. The structural description provides information on contextual details that are relevant to the phenomenon of interest. In the current study, these were factors described in the narratives that may have influenced the respondents' experiences in the aftermath of sexual violence perpetration, with particular attention to the social context. The contextual themes coded in the current analysis, including the social context, were not intended to relay information on some objective reality, but rather indicated the respondents' subjective experiences. In line with discursive analysis, the current analysis not only looked at the experiences of perpetrators, but also the way in which their narratives were constructed. With discursive analysis, the elusive task of obtaining a "true" analysis of the respondents' inner experiences does not invalidate the interpretation.

\subsubsection{Testing and coding phase}

The validity of qualitative research lies within the iterative nature of the analytic process (Morse, Barrett, Mayan, Olson, \& Spiers, 2002). Throughout the process of coding the narratives, we repeatedly checked that the codes fit with the data and were applied predictably. In order to ensure consensus and reliability for the way in which codes were applied to the data, inter-rater reliability was assessed early in the analytic process, once $25 \%$ of the data had been 
coded by both researchers using the agreed upon set of codes. This helped determine any areas of confusion in the codes and definitions. Below satisfactory agreement $(\kappa<.60$; Stemler, 2001), was resolved through adapting the code conceptualization to ensure a better fit with what was explicit in the data. Once consensus had been reached with satisfactory inter-rater reliability, the primary researcher coded the remaining $75 \%$ of the data.

\subsection{Interpretation}

Miles et al. (2014) provided the guidelines for maintaining objectivity when interpreting the findings. They argued for drawing logical connections between themes based on patterns that appear in multiple cases. In the current study, this included links between certain contextual elements and specific psychological responses to perpetration. The validity of the relationship between themes is supported by identifying the pattern across multiple cases, examining cases that do not fit the pattern, considering alternative explanations, and identifying areas that remain uncertain. The interpretation is further strengthened if it can be connected to past theory. In the current study, conclusions drawn from the data are in line with these guidelines proposed by Miles et al. (2014).

\section{RESULTS}

The purpose of this study was to examine the primary emotional reactions to perpetrating sexual violence, and the contextual and psychological features that co-occurred with these primary reactions. The analysis revealed four primary themes relating to the psychological outcomes of sexual violence perpetration: remorse, shame, depression, and anger. These four outcomes are negative emotional reactions directed at the perpetrator's behavior (remorse), the perpetrator himself (shame), the victim or women in general (anger), or generalized (depression). The theme of anger is presented with a caveat: the respondents whose narratives included anger 
frequently denied responsibility for the incident. Nevertheless, their narratives still shed light on outcomes of sexual violence perpetration. The four themes are discussed with attention to cooccurrences between psychological outcomes and salient contextual features. When applicable, I relate the themes back to the theoretical models outlined in the introduction.

The perpetrator narratives have been quoted exactly without changing language or spelling, although some narratives have been shortened in the interest of space. Because the narratives describe first-hand accounts of sexual violence perpetration, the quotations below contain graphic details and language that may be upsetting to the reader.

\subsection{Shame}

Shame emerged as a prominent theme in several narratives. Shame was characterized by a negative self-concept following the sexual violence perpetration. Although shame and remorse share overlapping conceptual features, shame is self-directed. The event is seen as evidence of a flawed self. For example, the respondent quoted below attributed his behavior to a fundamental flaw in his character:

I carried that mark on my conscience for years... I don't condone rape or sexual assault.

It's a terrible thing to impose your will upon another person. But I think to commit these sort of things shows a significant and somewhat demented flaw in your character. I always (and still) have had a lot of trouble connecting with other people. (Respondent 126)

Another respondent wrote about his struggles to accept himself following multiple acts of sexual violence perpetration, which resulted in his expulsion from college. His narrative begins:

Five years ago or so I was in the middle of a really bad breakup with someone who was manipulating me. Granted I could simply have cut her off but I was more naive at the 
time and didn't know how to say no to all the things she asked me for. In order to cope with my negative emotions I would pop Adderall during the day, smoke weed all the time, and drink until I passed out every night. Around this time I hooked up with a girl who lived down the hall from me. We were both really drunk, but she was near blackout and I was not nearly as gone. She invited me into her room, puked in the trash can, took her pants off and pulled me into bed. So I took this as her wanting to hook up and so we did ... I started drinking to the point where I would black out at least twice a week... I'd find a girl studying alone and strike up a conversation and eventually I would massage them and not pick up on obvious cues to go away since I was so drunk - or maybe willfully ignored them - but I didn't know how to stop myself. So after one particularly bad blackout I drag myself out of bed and go to class. Upon my return I find that I have an email telling me to go straight to Student Affairs. I do so and am promptly arrested and taken to the local municipal jail. Apparently during my blackout I went into a girl's room who I had a class with and volunteered with, and I woke her up by rubbing her thigh. She asked me what I wanted and I said 'you know what I want'. At which point she said she had a boyfriend, and instead of answering 'who cares' like she thought I might I turned into a mewling drunken bitch who eventually left the room. She told her roommates who told her to go to the campus security, who called the cops since the dorm was technically under the jurisdiction of local police... We had a mediated session where she dropped charges (from gross sexual imposition to trespass and disorderly conduct) and told me to go get help... So I kept going to class, until a week later I was called in and found out that three girls had come forward. One was the girl I drunkenly hooked up with (6 months ago at this point) who accused me of sexual assault. The other two were girls 
who I'd been talking to while blacked out who accused me of sexual harassment... Now it is five years later, and though I understand I crossed some lines and was a creep, I refuse to believe I was a rapist. I am still dealing with some self-shame issues that keep me from fully accepting myself but I hope with work I can become the most complete human I can be. (Respondent 311)

This respondent expressed shame when he indicated that he has had difficulty accepting himself. However, although this respondent related a story that meets the legal definition for rape, he rejected the label "rapist." He further denied his role as the aggressor by placing himself in the position of a victim. He introduced his narrative, "five years ago or so I was in the middle of a really bad breakup with someone who was manipulating me." His ex-girlfriend was not involved in any of the acts of sexual violence he described, so the choice to introduce his narrative with this information deserves attention — he began his story by explaining that he was the victim of manipulation.

In another example, the respondent quoted below expressed shame ("I feel like an awful person") yet also rejected the label "rape:"

I got peer pressured in to hooking up with this girl. I kept saying I didn't want to and my friends kept saying I had to lose my virginity. They say this for about a week and finally new years come so I figured might as well. We are both completely wasted and go to a room. I was to drunk to get it up so I fingered her and ate her out but she wasn't really into it. So I stopped and then threw up all over her and I passed out. I guess she ran out and told them I raped her. She never said stop or anything but I could see how she could have froze up in fear. I don't doubt she feels molested and I feel like an awful person but it wasn't rape (Respondent 178). 
Respondent 178 also described an incident that meets the legal definition of rape, as he described the victim as "completely wasted." The tension between feeling like an awful person and rejecting the label "rape" mirrors pathway 2 of the Cyclical Model of Shame and Sexual Violence depicted in the introduction (see Figure 1). According to the model, negative selfimage gives rise to cognitive distortions, which can include minimizing the significance of the event. By rejecting the label "rape," perpetrators might be attempting to minimize the significance of the event in order to protect their self-image.

\subsubsection{Shame, perpetrator alcohol use, and consent confusion.}

There were other ways respondents who expressed shame appeared to minimize their responsibility. Specifically, shame co-occurred with both themes of consent confusion and perpetrator alcohol use. For example, Respondent 178 and Respondent 311 reported being heavily intoxicated at the time of the assaults. Although there is no reason to doubt the veracity of this claim, the choice to include this detail in the narrative may represent an effort to show that this behavior was atypical for the respondent. By pointing out that he was intoxicated at the time, the perpetrator is also externalizing blame onto other factors (e.g., alcohol). Respondent 311's narrative exhibits a tendency to place blame on a variety of external factors, including alcohol, drugs, and a manipulative ex-girlfriend.

Several narratives that included shame also included consent confusion. Consent confusion was coded when the perpetrator stated that he believed that the sexual activity was consensual when it happened. Reports of consent confusion might indicate that the perpetrator was trying to place himself in a more favorable light. Consequently, by communicating that he believed the event was consensual, and by externalizing blame, the perpetrator who experienced 
shame may have been protecting his self-image and arguing that he was not rapist, although maybe still a "creep."

\subsection{Remorse}

For this analysis, remorse was defined as regret or feelings of guilt about the event without an indication that the respondent viewed himself negatively. Research supports differentiating between shame and guilt (Cohen, Wolf, \& Insko, 2011; Robinaugh \& McNally, 2010; Tangney, Wagner, Fletcher, \& Gramzow, 1992). Similarly, we found remorse (i.e., guilt) and shame appeared independently and were easily distinguished from one another, as shown by the strong inter-rater reliability. They were also differentially associated with various predictors. Remorse is not necessarily less severe than shame. Instead, the negative emotion is directed at the specific behavior rather than the whole self. The following example shows a respondent who expressed remorse about sexually assaulting an acquaintance.

However badly I feel about it, and I do feel fucking revolted about it, I can only imagine she feels worse. I would literally sell my soul to be able to take that night back. If there's any silver lining, and I know that any silver lining to such a thing is FUCKING TINY by comparison to how much I hurt her, it's that what happened made me a better man and drove me to be more active in feminism. I now would never ever EVER do something like that again, and in all my relationships since have always been respectful of my girlfriends when they dont want to. But that's it. It's an important lesson to learn but I really fucking wish I could have learned it without hurting someone like I did.

(Respondent 41)

Respondent 41 described immense regret ("I would literally sell my soul to take that night back"), yet he did not take his behavior as evidence that he is fundamentally flawed in some 
way. Instead, he expressed motivation toward self-improvement because of the event. He also did not attempt to downplay the severity of his behavior by externalizing blame or rejecting certain labels. The narrative below presents a similar case of remorse and commitment to selfimprovement:

MUCH later I realized that I had basically assaulted her, and that was why she broke up with me. (I was an overdramatic immature jerk at the time too I guess) I still think about it sometimes, and I feel terrible. It took a very long time for me to get over her. Dated another girl immediately after for many months, wishing it was this first girl the whole time. Then I met someone who really helped me get past her. I've never done anything like that ever again, and never will. I just wish I hadn't learned that lesson in that way, and that she had to suffer for it. (143)

\subsubsection{Remorse and self-growth}

The theme of self-growth co-occurred more strongly with remorse than with the other

three primary psychological themes. Self-growth was coded when the respondent indicated that following the perpetration, he was actively working toward being a better person, or actively working to prevent another act of perpetration. This finding is in line with current theory on guilt: because guilt is focused on a specific behavior while leaving the self-concept intact, it can function as a prosocial emotion (Robinaugh \& McNally, 2010; Tangney et al., 1992). The reparative effect of guilt or remorse is evidenced by the respondents' stated commitment to not repeat their behavior and their concern for the victim's well-being.

\subsection{Depression}

Depression following sexual violence perpetration emerged as a salient theme in several narratives. In this analysis, depression was coded when respondents explicitly wrote about 
depressed affect or suicidality as a result of perpetration. In some cases they admitted wrongdoing, while in others they claimed to be wrongfully accused. The following example demonstrates the emergence of suicidality after the respondent was adjudicated for sexual violence and subsequently rejected by his peers:

My friends from college, the few who found out, immediately treated me like I was Ted Bundy or some other piece of human trash and cut ties. I am not saying any of this to slander the girl who accused me. But there isn't a day that passes, there has not been since this happened more than a decade ago, that the thought of suicide has not crossed my mind. That word "Rape" will follow me to my grave. I could be the best person on Earth and it will still follow me. The only reason I haven't just done it, jumped off the Golden Gate Bridge or put my head in an exit bag, is because I know deep down my family still loves me. (Respondent 200)

\subsubsection{Depression and social isolation}

Nearly all instances of suicidality among perpetrators were accompanied by feelings of social ostracism following the assault. Respondent 200, quoted above, conveyed daily suicidal thoughts tied specifically to being socially outcast and bearing the label "rapist," rather than being tied to the actual sexual violence. Similarly, the following example contains a perpetrator's description of depression and suicidal ideation following social rejection:

I was so drunk I turned on the light to get a better look, then quickly realized that it would wake her up and turned the light off. But it did wake her and she got up and ran out. I woke up feeling the worst feelings about myself and my actions. I couldn't believe I could let myself go as far as to molest a good friend. I have never had many friends. She told at least some of my friends and my roommate. He kicked me out, and I lost all my 
friends. I still do not know how I live after this. I told my dad. He was not of any help, just told me not to tell my mom or my sisters because they wouldn't understand. I wish I knew how to apologize for this. I wish my friends could have the courage to help me. Sometimes I wish I had never promised myself that I would never commit suicide (Respondent 217).

This respondent, like Respondent 200, described feeling at a loss for how to move forward, which gives both narratives a sense of hopelessness. Respondent 200 explained that even being the best person would not free him from the label "rape." Respondent 217 described both not knowing how to apologize and not having friends to help him move forward. His narrative places responsibility for his current mental state on himself and his lack of social support.

The respondent in the next example related a period of depression after finding out that a sexual encounter he had thought was consensual was perceived by the victim as rape. In this case, there was no explicit indication that he was socially ostracized as in the previous examples.

I found out she felt like I had raped her, I was so blown away by this I had no idea what to do. I was confused and hurt and just felt like shit. I talked to her about it and we worked a lot of stuff out, she said I was one of the nicest guys she's ever met and knew I would never hurt her on purpose and we were all good for a while. It wasn't the same though, there was always this awkwardness between me and her from that point on. Eventually I just stopped talking to her all together. I have never in my life felt as shitty and depressed as when she told me that she felt what happened was rape. The depression made me have to drop out of school and go live back home. My parents thought I was gonna try to kill myself so I started taking medication and going to therapy and it actually 
helped a little. I'm over my depression now but I never, and will never, feel as low as I did because of that night. (Respondent 149)

Although this respondent was not rejected by either the victim or his peer group, his depression began when the label "rape" was applied to his experience. As such, this narrative resembles Respondent 200's narrative when he explained, "That word 'Rape' will follow me to my grave." As in the case of respondents who expressed shame, respondents who related depression provided evidence for a link between negative emotions and the word "rape," although the men that expressed shame primarily rejected the term. Rape is socially reprehensible, and as such, the label "rape" or "rapist" may represent actual or feared ostracism.

\subsection{Anger toward the victim}

Thus far, I have discussed negative emotional reactions that are directed toward the self (shame), the behavior (remorse), or generalized (depression). Yet, some respondents expressed negative reactions directed toward the victim—or the alleged victim. Many of these respondents perceived the sexual interaction as consensual and expressed anger at being falsely accused of rape or sexual violence perpetration.

In the following example, Respondent 529 explained that whenever he thought about a past experience of perpetration, his first reaction was to blame the victim:

I know making out doesn't mean yes to sex, but I really thought that she wanted it. I don't remember her saying no, but I believe her that she said it. i feel godawful and think about it every day. my thoughts go from "she didn't say no she just thinks i raped her because she's an attention grabber" to "holy shit how can i think like that. that's just me trying to feel less guilty about the situation, you ARE a RAPIST, YOU RAPED HER" to "ok it's in the past, just don't do it again, you are a good person" she texted me a few months ago 
too. she has a few good friends that she's told and she's in therapy so hopefully she can live with it, even if it's going to be hard. (Respondent 529)

This narrative exemplifies the relationship between anger and shame. Although the respondent at times blamed the victim, he then chastised himself: "you ARE a RAPIST." He expressed shame through his shock and disturbance at his behavior and his capacity to blame the victim, "holy shit how can I think like that." He then moved past shame by reminding himself that he is a good person. The initial link between shame and anger is in line with pathway 2 in the Cyclical Model of Shame and Sexual Violence presented earlier. Negative self-concept that follows perpetration gives way to cognitive distortions that serve the purpose of protecting one's self-image. In this case, the cognitive distortion was accusing the victim of lying in order to seek attention. The moments when he thought of her as an "attention grabber" may also be evidence of a lack of empathy for her, which reflects pathway 3.

\subsubsection{Anger and hostility toward women}

Several respondents provided narratives that placed blame on the victim and expressed anger and hostility. However, these narratives, unlike Respondent 529's narrative above, did not describe vacillating between shame and anger. Instead, the majority of these narratives expressed anger at the women for making the respondents feel like perpetrators or hostility toward women generally. The content of these narratives does not necessarily describe perpetration; however, in light of Respondent 529's narrative, it is possible that cognitive distortions that place blame on the victim rather than the perpetrator are at play in these narratives as well.

One cannot rule out the possibility that these respondents truly did not perpetrate sexual violence, and their anger or feelings of betrayal are the result of a false accusation. That said, many narratives that fell into this category described common rape myths, most notably, that 
women generally lie about rape. They also tended to use language that was hostile toward women. Both rape myth acceptance and hostility toward women have been found to predict sexual violence (e.g., Abbey et al., 2007; Bohner, Jarvis, Eyssel, Siebler; Malamuth et al., 1991). Additionally, these men chose to respond to a thread that asked specifically about experiences of perpetrating sexual violence. Therefore, these narratives warrant inclusion in a discussion of emotional reactions to (accused) sexual violence perpetration that may give way to future sexually violent behavior. The narrative below clearly demonstrates that pattern of feeling wrongly accused and endorsing the rape myth that women "cry false rape," while using language that is hostile toward women:

Am I a rapist? Well fuck no. Did I feel like one anyway? Oddly, yes. Some of the stories in this thread don't involve actual rape, just situations where someone with a highly biased opinion would try to make the guy in the situation feel like he had done something wrong. This happens way. too. fucking. much. My kneejerk reaction to a girl saying she's been raped has become "uh huh yeah whatever bitch" because I've heard women cry false rape way too many times on my buddies, as a way to get out of things or as a way to get sympathy...When women assault men they often do it insidiously through lies, social manipulation and by harming their image and self worth and our society prevents men from retaliating or defending themselves against this. Is it as damaging as being physically raped? Who cares? Do assaults need to be placed in some kind of pecking order? All attacks of a sexual nature are bad and destroying a guy's life by casting him as a rapist when he's done nothing wrong is just as soul-destroying as being raped, particularly because the guy is being made to feel like he's the aggressor in a situation where he's actually being attacked.(Respondent 557) 
Although this respondent adamantly denied committing rape, he admitted to feeling like a rapist. This suggests either that he doubts his innocence, or that being seen as a rapist by others is enough to feel like a rapist. In the former, this narrative resembles a pattern discussed in the section on shame: the respondent's negative self-concept following the event is coupled with an explicit denial of the labels "rape" or "rapist." This pattern was discussed as evidence of cognitive distortions that protect against shame (pathway 2). On the other hand, if this respondent was simply reacting to the label placed on him by the victim or his social circle, this narrative then highlights an important pattern that emerged in the discussion on depression; the social response to actual or perceived sexual violence has potentially profound psychological consequences for the accused perpetrator. In either case, this respondent argued that he and some of the other respondents to the Reddit post were victims of manipulative assaults by women, a position that does not acknowledge the high incidence of male to female sexual violence or empathizes with the victim's perspective.

Not all negative reactions toward the (alleged) victim entailed a denial of responsibility. In the following example, Respondent 579, clearly admitted to rape, and he still expressed hostility toward the victim through denigrating language.

I tore her shirt off and she pulled away. I fucked her there and walked away, disgust in my eyes as she told me how pathetic I was. She railed something about her innocence and how I was a monster. I didn't care. I had been pushed over an edge and my primal instinct was there to defend itself... I called her a whore as I left. (Respondent 579) Although this respondent admitted to rape, he also blamed the victim for pushing him "over an edge." He further evaded responsibility by attributing his behavior to a "primal instinct." By blaming the victim and his primal instinct, he could be trying to minimize his culpability. 
The examples above indicate that negative reactions directed toward the victim entail various facets. First, not all respondents believed they committed rape, and they felt anger toward the women who accused them. They also at times endorsed rape myths and used hostile language to talk about women. Second, some respondents acknowledged that the incident was non-consensual, but still expressed hostility toward the victim and blamed her for instigating his behavior. Narratives of acknowledged rape or self-proclaimed innocence that contain hostility toward women and rape myth acceptance are important to the discussion of perpetration outcomes. As in the case of Respondent 520, victim blame may be a cognitive distortion that protects against negative emotions. Further, past findings suggests that compared to non-hostile men, respondents who expressed hostility toward women have greater likelihood or perpetrating sexual violence (e.g., Malamuth et al., 1991; Abbey \& Jacques-Tiura, 2011).

\section{DISCUSSION}

The purpose of this study was to examine the psychological outcomes of perpetrating sexual violence among self-identified perpetrators. The analysis revealed 4 salient emotional outcomes to perpetrating sexual violence among the narratives posted on Reddit.com: shame, remorse, depression, and anger. Each of these outcomes co-occurred with different contextual or psychological themes (e.g., consent confusion, social isolation, and self-growth). The cooccurrence of the primary emotional themes with other second-level themes sheds light on the factors that contribute to these emotional reactions and the influence of the emotional reactions on how the perpetrator interprets and communicates details of the assault. First, the results indicated a relationship between shame and externalization of blame that is in line with Cyclical Model of Shame and Sexual Violence presented in the Introduction (see Figure 1). Additionally, 
across all four primary psychological outcomes, perpetrators highlighted the influence of social factors on their psychological responses to perpetration.

In the Cyclical Model of Shame and Sexual Violence, which incorporated theoretical elements from Wolf (1989), Marshall et al. (2009), and Stuewig et al. (2010), shame following perpetration leads to cognitive distortions (e.g., victim blame, minimization of the harm inflicted; pathway 2), or reduced empathy for the victim (pathway 3). Both lack of empathy for the victim, and cognitive distortions lead back to sexual violence perpetration (pathways $4 \& 5$ ), as reduced empathy is a predictor of perpetration (Abbey et al., 2007; Wheeler et al., 2002), and cognitive distortions, such as victim blame, prevent the perpetrator from taking steps to correct his behavior. In the present study, this pattern appeared in the strong co-occurrence between shame and reports of consent confusion and perpetrator externalization of blame. These perpetrators may have attempted to reduce the experience of shame by blaming external factors (e.g., alcohol use) and by explaining that they initially believed the assault to be consensual. By blaming external factors, the perpetrators who expressed shame may be less likely to take steps to correct their behavior. This is in contrast to perpetrators who expressed remorse and explicitly stated that they would not perpetrate again: "I now would never ever EVER do something like that again" (Respondent 41). Figure 2 presents an example of a perpetrator response that includes shame, as explained by the Cyclical Model of Shame and Sexual Violence.

On the surface, Respondent 311 's narrative appears to be a counter-example: he expressed shame and indicated self-growth. "Now it is five years later, and though I understand I crossed some lines and was a creep, I refuse to believe I was a rapist. I am still dealing with some self-shame issues that keep me from fully accepting myself but I hope with work I can become the most complete human I can be" (Respondent 311). Nevertheless, unlike the two respondents 
quoted in the Results section on remorse, Respondent 311 did not acknowledge the gravity of his actions or the potential harm to the victims in his narrative. Instead, he portrayed his college's disciplinary proceeding as unfair to him: "It was a private school so despite there being a lack of any evidence beyond their word vs mine I was found guilty." Therefore, his effort to become a “complete human" does not appear to indicate a concerted effort to correct his sexually violent behavior, as he did not claim responsibility for this behavior. Rather, his focus for selfimprovement is nebulous and seems to relate more to improving his own self-evaluation than improving his behavior: "I am still dealing with some self-shame issues that keep me from fully accepting myself but I hope with work I can become the most complete human I can be." Therefore, Respondent 311 's response in the aftermath of a sexual assault accusation is consistent with theories relating to shame and with the Cyclical Model of Shame and Sexual Violence. Specifically, the model expects that the perpetrator is focused more on alleviating his own distress related to a negative self-image than on understanding the victim's experience (pathway 3). Furthermore, the perpetrator reduces his own culpability by minimizing the significance of the event (e.g., referring to his behavior as crossing the line, rather than rape; pathway 2).

The anger response also aligns with certain aspects of the Cyclical Model of Shame and Sexual Violence, despite the fact that several of these respondents did not acknowledge having perpetrated sexual violence. According to the model, some perpetrators may reduce shame by blaming the victim or denying responsibility. Therefore, if the respondents who expressed anger actually did perpetrate sexual violence, they may have been protecting themselves from the experience of shame by denying responsibility. The pathway from shame to anger through victim 
blame is apparent in Respondent 529's narrative. This respondent's reaction transitioned from anger and victim blame to shame and guilt.

Although the themes of shame and anger did not consistently overlap in the current study, they shared important similarities: externalization of blame and rejection of the "rape" label. Prior research has found a strong relationship between shame, anger, hostility, externalization of blame, and aggression (Stuewig et al., 2010; Tangney et al., 1992). For example, Tagney et al. (1992) found that proneness to shame correlated with anger reactivity and a tendency to blame others. Additionally, Stuewig et al. (2010) found that shame indirectly predicted aggression through externalization of blame. This suggests that the tendency to externalize blame among respondents in the current study warrants particular attention for preventing future violence perpetration.

Additionally, several respondents suggested that their emotional reaction to perpetrating sexual violence was connected to the social context. In Figure 3, I present examples that highlight the social significance of the four primary emotional themes and their co-occurring contextual themes. The strong co-occurrence between social isolation and depression exemplifies how social reactions to sexual violence can influence perpetrator outcomes. In two of the three narratives presented on depression, the respondents described how peer rejection following sexual violence perpetration preceded depression and suicidal ideation. Figure 4 depicts this relationship between negative social appraisal and depression. This finding builds upon existing research on the importance of peer attitudes in sexual violence. Prior research has indicated that perceived peer approval of sexual violence contributes to a person's sexually violent behavior (Franklin, Bouffard, \& Pratt, 2012; Jacques-Tiura et al. 2015; Swartout, 2013). Results from the current study indicate that peer attitudes are also important in the aftermath of sexual violence, 
and they can shape how the perpetrator reacts to the event. DeKeseredy (1990) argued that a perpetrator's peers provide a favorable interpretive lens in the aftermath of sexual violence to protect him from stress. The results from the current study indirectly support DeKeseredy's theory by demonstrating that when peer support is denied, perpetrators can suffer from severe emotional consequences.

The respondents' focus on the word "rape" across the primary emotional themes also indicates a concern for the social appraisal of the perpetrators' actions. Labels carry important social significance, and the label "rapist" can overshadow other elements of one's identity in the eyes of others. As Respondent 200 pointed out, "I could be the best person on Earth and [the word rape] will still follow me." Consequently, several respondents rejected the label by blaming external factors or by accusing the victim of lying. For example, Respondent 557 berated women for unfairly labelling men as rapists, which he argued destroys their lives.

The significance of social contexts is also apparent in the way these narratives were constructed. A discursive interpretation of the narratives allowed for a critical examination of the choice to include certain elements in a narrative and convey the story in a particular way when the same event could be communicated differently (Willig, 2012). For instance, the statement, "it wasn't rape," does not add any factual information; yet, many respondents used this or a similar statement as an interpretation of their experience.

The choices made in framing narratives are particularly important when considering that the respondents chose to tell their stories in a public forum. Several respondents expressed frustration that after being accused of perpetrating sexual violence, they did not get to share their side of the story. One respondent explained, “All my friends think I am a rapist. My only option is to leave town even though she never went to the police about it. The truth is that I feel 
incredibly violated by her, but nobody cares because I'm a male" (Respondent 483). Likewise, Respondent 557 proclaimed that men do not have a voice to defend themselves against false accusations: "our society prevents men from retaliating or defending themselves." Both of these respondents used this forum to share their sides of the story that they believed had been silenced before. As such, social dynamics do not only play out within the narratives, but also when considering the purpose of these narratives. The fact that many narratives appear to be framed to reduce culpability (e.g., by blaming alcohol or placing the perpetrators in the position of the victims) and publicly shared tells us that the perpetrators may seek some type of social acceptance.

\subsection{Clinical and Policy Implications}

The results from this study indicate the presence of emotional reactions that could give rise to self-harm or future sexual violence perpetration. Some respondents indicated thoughts of suicide, while other narratives included elements, such as externalization of blame, that are predictive of aggression (Stuewig et al., 2010). These findings can shed light on the development of therapeutic interventions for perpetrators. Although prior research indicates elevated risk for self-harm among sexual offenders (Jeglic, Spada, \& Mercado, 2013; Stinson \& Gonsalvez, 2014), this research has focused on adjudicated offenders and child sex offenders. The present study indicates that suicide may be a risk for non-adjudicated perpetrators and should be assessed among perpetrators seeking treatment. Second, the results from the current study have important implications for the treatment of shame. The findings in many ways align with the Cyclical Model of Shame and Sexual Violence (Figure 1), suggesting that treating shame is especially important for preventing repeat perpetration. 
Pollard (1994) presented treatment principles for sexual violence perpetrators on college campuses that emphasize the need for perpetrators to accept complete responsibility, yet also work toward self-forgiveness. Self-forgiveness can in turn help reduce shame, which Pollard acknowledged contributes to the perpetration cycle. Likewise, Marshall et al. (2009) argued that treatment for perpetrators should entail enhancing their self-esteem. In order to do this, the therapist points out that the sexually violent behavior does not define the perpetrator's entire character. Furthermore, they argued that enhancing self-esteem may be a necessary first step before the perpetrator can accept full responsibility.

The findings from the current study reinforce the importance of reducing perpetrators' negative self-image. However, this may also entail a focus on the perpetrator perception of the social reaction to his behavior. Just as peer disapproval is important for treatment of perpetrators who expressed depression, peer disapproval may also influence perpetrators' experience of shame. Theoretical accounts of shame propose it is rooted in either actual or imagined disapproval from others (Andersen \& Chen, 2002; Baldwin, 1997). Shame involves a negative self-evaluation, and self-evaluation is influenced by perceived or actual evaluation by others (Andersen \& Chen, 2002; Sheikh, 2014). Therefore, therapeutic interventions should examine how the perpetrator might be affected by his perception of his peers' reactions to his behavior.

\subsection{Limitations and Future Directions}

The narratives used in this study were provided by anonymous Reddit users who had no contact with the researchers. This presented unique challenges for determining the legitimacy of the claims made in this thesis. Miles et al. (2014) provided a set of guidelines for interpreting qualitative results, which were followed to the extent possible for the current study.

Nevertheless, not all of the guidelines could be adhered to due to the data characteristics. For 
example, when relating two variables, Miles et al. (2014) argued for assessing the extent to which changes in one variable regularly coincide with changes in the other. Because the respondents were free to include any details they thought relevant, each narrative included some themes but not others, making it difficult to verify the relationships between variables across all narratives. For example, it is not clear whether respondents who expressed remorse were also concerned with the label "rape," simply because the label "rape" was infrequently mentioned in narratives containing remorse. For the same reasons, the data were not amenable to uncovering intermediate variables that could explain the relationship between two co-occurring themes.

Ultimately, based on the data available, it is impossible to know the experience of the perpetrators beyond what they presented in their narratives. For example, although several narratives contained elements that were in line with the Cyclical Model of Shame and Sexual Violence, we do not have evidence on whether these respondents go on to perpetrate again in the future. Future research could address this remaining question with a longitudinal study that examines whether shame following sexual violence perpetration predicts future violence perpetration, and whether this relationship is mediated by reduced empathy or cognitive distortions. Furthermore, a longitudinal study could look at whether levels of shame associated with past perpetration change overtime.

Additionally, it was not clear from the data whether the respondents who expressed anger for being falsely accused had actually perpetrated sexual violence and were engaging in cognitive distortions in order to protect their self-image. Although they denied responsibility, these respondents also chose to respond to a question that was specifically posed to sexual violence perpetrators. Future research could clarify the relationship between sexual violence, anger, and denial of responsibility with a mixed methods analysis that assesses for correlations 
between shame-proneness and anger among men who report being accused of perpetration, with a qualitative analysis that looks for the presence of blame externalization within their narratives of the incident.

\subsection{Conclusion}

The purpose of this study was to understand the psychological outcomes of perpetrating sexual violence in order to better understand processes that give rise to repeat perpetration. A review of the literature on theoretical models of repeat sexual violence perpetration allowed for the creation of a hypothesized model of the relationship between negative psychological outcomes and repeat perpetration — the Cyclical Model of Shame and Sexual Violence. According to this model, shame following sexual violence gives rise to cognitive distortions (e.g. minimizing the significance of the event, blaming the victim) or reduced victim empathy through the perpetrator's undue focus on relieving his own negative affect. Both pathways may reduce the likelihood that the perpetrator corrects sexually violent behavior.

In the current study, 75 first-hand narratives of sexual violence perpetration, posted on Reddit.com, were analyzed using qualitative text analysis (Kuckartz, 2014). The results revealed four primary emotional responses to perpetrating sexual violence: shame, remorse, depression, and anger. Each emotional response was associated with different contextual features that appeared in the narratives. Shame co-occurred with reports of perpetrator alcohol use and consent confusion; remorse co-occurred with perpetrators' stated self-growth; depressed affect co-occurred with social isolation in the aftermath of perpetration; and anger co-occurred with attitudes that are hostile toward women. The findings of this study are in several ways in line with the Cyclical Model of Shame and sexual violence. Additionally, the results indicate the importance of the social context when considering the four primary psychological outcomes 
identified in this study. This research has important implications for the treatment of perpetrators and supports the idea that self-image and perceived social context may be important treatment targets. 


\section{REFERENCES}

Abbey, A., \& Jacques-Tiura, A. J. (2011). Sexual assault perpetrators' tactics: associations with their personal characteristics and aspects of the incident. Journal of Interpersonal Violence, 26(14), 2866-89. doi:10.1177/0886260510390955

Abbey, A., Parkhill, M. R., Clinton-Sherrod, A. M., \& Zawacki, T. (2007). A comparison of men who committed different types of sexual assault in a community sample. Journal of Interpersonal Violence, 22(12), 1567-80. doi:10.1177/0886260507306489

Andersen, S. M., \& Chen, S. (2002). The relational self: An inter-personal social-cognitive theory. Psychological Review, 109(4), 619-645. doi:10.1037/0033-295X.109.4.619

Baldwin, M. W. (1997). Relational schemas as a source of if-then self-inference procedures. Review of General Psychology, 1, 326-335. doi: 10.1037/1089-2680.1.4.326

Bohner, G., Jarvis, C. I., Eyssel, F., \& Siebler, F. (2005). The causal impact of rape myth acceptance on men's rape proclivity: Comparing sexually coercive and noncoercive men. European Journal of Social Psychology, 35(6), 819-828. doi:10.1002/ejsp.284

Breiding, M. J., Basile, K. C., Walters, M. L., Chen, J., \& Merrick, M. T. (2014). Prevalence and characteristics of sexual violence, stalking, and intimate partner violence victimization: National intimate partner and sexual violence survey, United States, 2011. Surveillance Summaries, 63(8), 1-18.

Bronfenbrenner, U. (1977). Toward an experimental ecology of human development. American Psychologist, 32, 513-531. doi:10.1037//0003-066x.32.7.513

Carver, C. S., \& Scheier, M. F. (1990). Origins and functions of positive and negative affect: A control-process view. Psychological Review, 97(I), 19-35. doi:10.1037//0033295x.97.1.19 
Centers for Disease Control and Prevention (2014). Sexual violence. Injury Prevention and Control: Division of Violence Prevention. Retrieved from http://www.cdc.gov/violenceprevention/sexualviolence/

Cohen, T. R., Wolf, S. T., Panter, A. T., \& Insko, C. A. (2011). Introducing the GASP scale: a new measure of guilt and shame proneness. Journal of Personality and Social Psychology, 100(5), 947-966. doi:10.1037/a0022641

Creswell, J. W. (2007). Qualitative inquiry and research design: Choosing among five approaches. Thousand Oaks, CA: SAGE Publications, Inc.

DeKeseredy, W. S. (1988). Woman abuse in dating relationships: The relevance of social support theory. Journal of Family Violence, 3(1), 1-13. doi: 10.1007/bf00994662

DeKeseredy, W. S. (1990). Male peer support and woman abuse: The current state of knowledge. Sociological Focus, 23(2), 129-139. doi:10.1080/00380237.1992.10570559

DeKeseredy, W. S. \& Kelly, K. (1995). Sexual abuse in Canadian university and college dating relationships: The contribution of male peer support. Journal of Family Violence, 10(1). doi:10.1007/bf02110536

Duggan, M. \& Smith, A. (2013). 6\% of online adults are reddit users. Pew Research Center. Retrieved from http://pewinternet.org/Reports/2013/reddit.aspx

Emerson, P. \& Frosh, S. (2004). Critical narrative analysis in psychology. New York, NY: Palgrave Macmillan.

Evans, C., Ehlers, A., Mezey, G., \& Clark, D.M. (2007). Intrusive memories in perpetrators of violent crime: Emotions and cognitions. Journal of Consulting and Clinical Psychology, 75, 134-144. doi:10.1037/0022-006x.75.1.134 
Franklin, C. A., Bouffard, L. A., \& Pratt, T. C. (2012). Sexual assault on the college campus: Fraternity affiliation, male peer support, and low self-control. Criminal Justice and Behavior, 39(11), 1457-1480. doi:10.1177/0093854812456527

Hall, G. C. \& Hirschman, R. (1991). Toward a theory of sexual aggression: A quadripartite model. Journal of Consulting and Clinical Psychology, 59, 662-669. doi:10.1037/0022$006 x .59 .5 .662$

Heise, L. L. (1998). Violence against women: An integrated, ecological framework. Violence Against Women, 4, 262-290. doi:10.1177/1077801298004003002

Hundt, N.E., \& Holohan, D.R. (2012). The role of shame in distinguishing perpetrators of intimate partner violence in U.S. veterans. Journal of Traumatic Stress, 25, 191-197. doi: $10.1002 /$ jts. 21688

Jacques-Tiura, A. J., Abbey, A., Wegner, R., Pierce, J., Pegram, S. E., \& Woerner, J. (2015). Friends matter: Protective and harmful aspects of male friendships associated with pastyear sexual aggression in a community sample of young men. American Journal of Public Health, 105(5), 1001-1007. doi:10.2105/AJPH.2014.302472

Joinson, A. (1999). Social desirability, anonymity, and Internet-based questionnaires. Behavior Research Methods, Instruments \& Computers, 31(3), 433-438. doi:10.3758/BF03200723

Jeglic, E. L., Spada, A., \& Mercado, C. C. (2013). An examination of suicide attempts among incarcerated sex offenders. Sexual Abuse: A Journal of Research and Treatment, 25(1), 21-40. doi:10.1177/1079063212447201

Kivisto, A. J., Kivisto, K. L., Moore, T. M., Rhatigan, D. L. (2011). Antisociality and intimate partner violence: The facilitating role of shame. Violence and Victims, 26(6), 758-774. doi: 10.1891/0886-6708.26.6.758 
Knight, R. A. \& Sims-Knight, J. E. (2004). Testing an etiological model for male juvenile sexual offending against females. Journal of Child Sexual Abuse, 13, 33-55. doi:10.1300/j070v13n03_03

Koss, M. P., Gidycz, C. A., \& Wisniewski, N. (1987). The scope of rape: Incidence and prevalence of sexual aggression and victimization in a national sample of higher education students. Journal of Consulting and Clinical Psychology, 55, 162-170. doi: 10.1037//0022-006x.55.2.162

Kuckartz, U. (2014). Qualitative text analysis: A guide to methods, practice and using software. Thousand Oaks, CA: SAGE Publications, Inc.

Maguen, S., Metzler, T. J., Bosch, J., Marmar, C. R., Knight, S. J., \& Neylan, T. C. (2012). Killing in combat may be independently associated with suicidal ideation. Depression and Anxiety, 29, 918-923. doi:10.1002/da.21954

Maguen, S., Metzler, T. J., Litz, B. T., Seal, K. H., Knight, S. J., \& Marmar, C. R. (2009). The impact of killing in war on mental health symptoms and related functioning. Journal of Traumatic Stress, 22(5), 435-443. doi:10.1002/jts.

Malamuth, N. M., Sockloskie, R. J., Koss, M. P., \& Tanaka, J. S. (1991). Characteristics of aggressors against women: Testing a model using a national sample of college students. Journal of Consulting and Clinical Psychology, 59, 670-681. doi: 10.1037//0022$006 x .59 .5 .670$

Marshall, W. L. \& Barbaree, H. E. (1990). An integrated theory of sexual offending. In W. L. Marshall, D. R. Laws, \& H. E. Barbaree (Eds.), Handbook of sexual assault: Issues, theories and treatment of the offender (pp. 363-385). NY: Plenum. 
Marshall, W.L., Marshall, L. E., Serran, G. A. \& O’Brien, M. D. (2009). Self-esteem, shame, cognitive distortions and empathy in sexual offenders: their integration and treatment implications. Offender Cognition \& Emotion, 15, 217-235. doi:

$10.1080 / 10683160802190947$

Miles, M. B., Huberman, A. M., \& Saldaña, J. (2014). Qualitative data analysis: A methods sourcebook (3rd ed.). Thousand Oaks, CA: SAGE Publications, Inc.

Morse, J. M., Barrett, M., Mayan, M., Olson, K., \& Spiers, J. (2002). Verification strategies for establishing reliability and validity in qualitative research. International Journal of Qualitative Methods, 1, 1-19.

Pollard, J. W. (1994). Treatment for perpetrators of rape and other violence. New Directions for Student Services, 65, 51-66. doi:10.1002/ss.37119946507

Pollock, P. H. (1999). When the killer suffers: Post-traumatic stress reactions following homicide. Legal and Criminal Psychology, 4, 185-202. doi:10.1348/135532599167842

Robinaugh, D. J., \& McNally, R. J. (2010). Autobiographical memory for shame or guilt provoking events: association with psychological symptoms. Behaviour Research and Therapy, 48(7), 646-52. doi:10.1016/j.brat.2010.03.017

Sheikh, S. (2014). Cultural variations in shame's responses: A dynamic perspective. Personality and Social Psychology Review, 18(4), 387-403. doi: $10.1177 / 1088868314540810$

Showers, C., \& Cantor, N. (1985). Social cognition: A look at motivated strategies. Annual Review of Psychology 36, 275-305. doi:10.1146/annurev.ps.36.020185.001423

Stemler, S. (2001). An overview of content analysis. Practical Assessment, Research \& Evaluation, 7(17). Retrieved from http://PAREonline.net/getvn.asp?v=7\&n=17 
Stinson, J. D., \& Gonsalves, V. (2014). Suicide attempts and self-harm behaviors in psychiatric sex offenders. Sex Abuse, 26(3), 252-270. doi: 10.1177/1079063213486935

Stuewig, J., Tangney, J. P., Heigel, C., Harty, L., \& McCloskey, L. (2010). Shaming, blaming, and maiming: Functional links among the moral emotions, externalization of blame, and aggression. Journal of Research in Personality, 44(1), 91- 102.

doi:10.1016/j.jrp.2009.12.005

Swartout, K. M. (2013). The company they keep: How peer networks influence male sexual aggression. Psychology of Violence, 3, 157-171. doi:10.1037/a0029997

Tangney, J. P., Wagner, P., Fletcher, C., \& Gramzow, R. (1992). Shamed into anger? The relation of shame and guilt to anger and self-reported aggression. Journal of Personality and Social Psychology, 62(4), 669-675. doi:10.1037/0022-3514.62.4.669

Thompson, M. P., Swartout, K. M., \& Koss, M. P. (2013). Trajectories and predictors of sexually aggressive behaviors during emerging adulthood. Psychology of Violence, 3(3), 247-259. doi:10.1037/a0030624

Van Vliet, K. J. (2010). Shame and avoidance in trauma. In E. Martz (Ed.), Trauma rehabilitation after war and conflict (pp. 247-290). New York, NY: Springer.

Van Winkle, E. P., \& Safer, M. A. (2011). Killing versus witnessing in combat trauma and reports of PTSD symptoms and domestic violence. Journal of Traumatic Stress, 24, 107 110. doi: $10.1002 /$ jts. 20614

Ward, T., Hudson, S. M, \& Keenan, T. (1998). A self-regulation model of the sexual offense process. Sex Abuse, 10, 141-157. doi:10.1177/107906329801000206

Wheeler, J. G., George, W. H., \& Dahl, B. J. (2002). Sexually aggressive college males: Empathy as a moderator in the 'Confluence Model' of sexual aggression. Personality 
and Individual Differences, 33, 759-776. doi:10.1016/s0191-8869(01)00190-8

White, J. W., \& Smith, P. H. (2004). Sexual assault perpetration and reperpetration: From adolescence to young adulthood. Criminal Justice and Behavior, 31(2), 182-202. doi:10.1177/0093854803261342

Willig, C. (1999). Applied discourse analysis. Berkshire, U.K.: Open University Press.

Willig, C. (2012). Qualitative interpretation and analysis in psychology. Berkshire, U.K.: Open University Press.

Wolf, S. C. (1989). A model of sexual aggression/addiction. Journal of Social Work \& Human Sexuality, 7(1), 131-148. doi:10.1300/j291v07n01_10 


\section{APPENDIX}

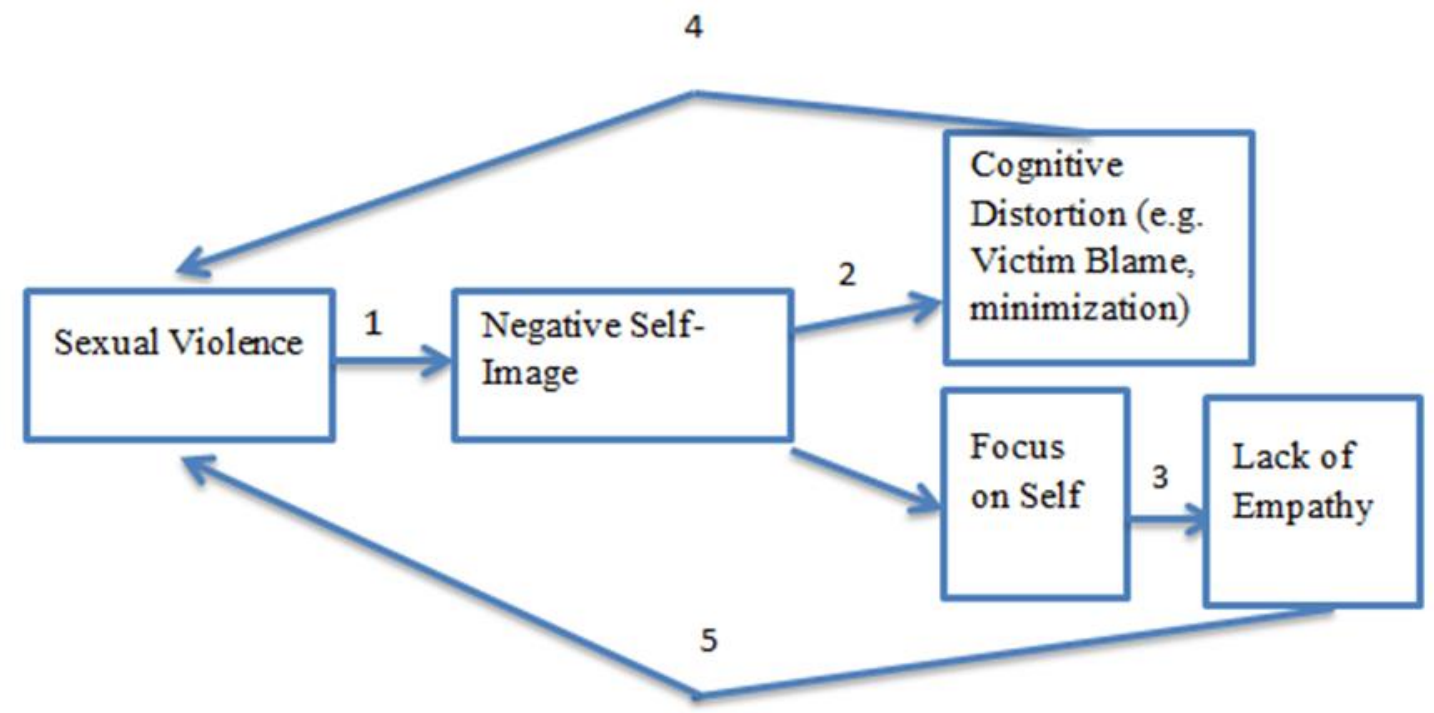

Figure 1. The Cyclical Model of Shame and Sexual Violence 


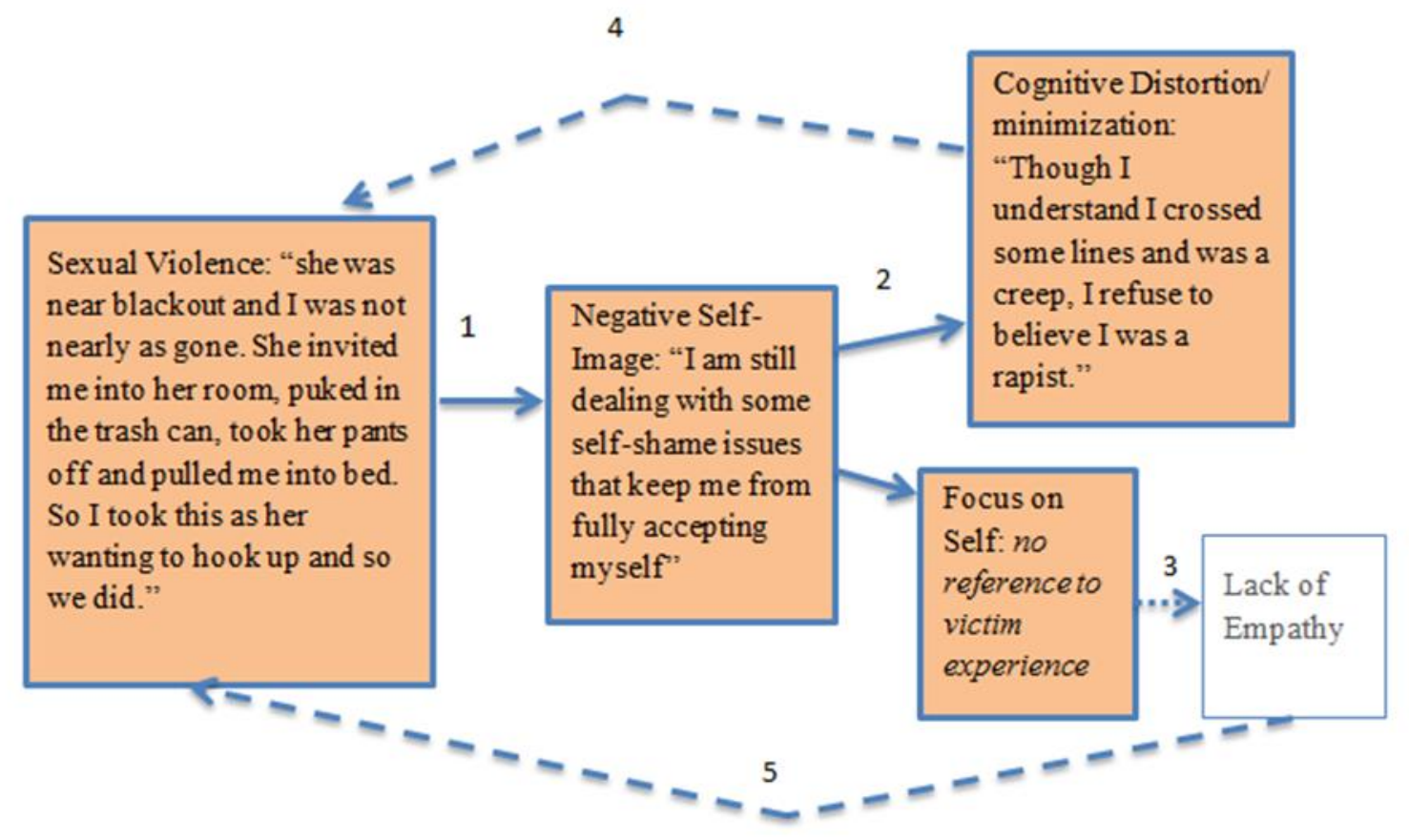

Figure 2. A narrative with shame broken down into the elements of the Cyclical Model of Shame and Sexual Violence. 


\begin{tabular}{|c|c|c|c|c|}
\hline & Shame & Guilt & Anger & Depression \\
\hline $\begin{array}{l}\text { Description of } \\
\text { emotion }\end{array}$ & $\begin{array}{l}\text { Negative emotion } \\
\text { directed at self: "I } \\
\text { don't doubt she } \\
\text { feels molested and I } \\
\text { feel like an awful } \\
\text { person but it wasn't } \\
\text { rape." }\end{array}$ & $\begin{array}{l}\text { Negative emotion } \\
\text { directed at } \\
\text { behavior: } \\
\text { "However badly I } \\
\text { feel about it, and I } \\
\text { do feel fucking } \\
\text { revolted about it, I } \\
\text { can only imagine } \\
\text { she feels worse." }\end{array}$ & $\begin{array}{l}\text { Negative emotion } \\
\text { directed at } \\
\text { victim: "Am I a } \\
\text { rapist? Well fuck } \\
\text { no. Did I feel like } \\
\text { one anyway? } \\
\text { Oddly, yes... My } \\
\text { kneejerk reaction } \\
\text { to a girl saying } \\
\text { she's been raped } \\
\text { has become "uh } \\
\text { huh yeah whatever } \\
\text { bitch"” }\end{array}$ & $\begin{array}{l}\text { Depressed mood } \\
\text { or suicidal } \\
\text { ideation: "The } \\
\text { only reason I } \\
\text { haven't just done } \\
\text { it, jumped off the } \\
\text { Golden Gate } \\
\text { Bridge or put my } \\
\text { head in an exit } \\
\text { bag, is because I } \\
\text { know deep down } \\
\text { my family still } \\
\text { loves me." }\end{array}$ \\
\hline $\begin{array}{l}\text { Co-occurring } \\
\text { themes }\end{array}$ & $\begin{array}{l}\text { Alcohol: "We are } \\
\text { both completely } \\
\text { wasted and go to a } \\
\text { room." } \\
\text { Consent } \\
\text { confusion: "She } \\
\text { never said stop or } \\
\text { anything but I } \\
\text { could see how she } \\
\text { could have froze up } \\
\text { in fear." }\end{array}$ & $\begin{array}{l}\text { Self- } \\
\text { improvement: "I } \\
\text { now would never } \\
\text { ever EVER do } \\
\text { something like } \\
\text { that again, and in } \\
\text { all my } \\
\text { relationships since } \\
\text { have always been } \\
\text { respectful of my } \\
\text { girlfriends when } \\
\text { they dont want } \\
\text { to." }\end{array}$ & $\begin{array}{l}\text { Hostility toward } \\
\text { women: "When } \\
\text { women assault } \\
\text { men they often do } \\
\text { it insidiously } \\
\text { through lies, social } \\
\text { manipulation and } \\
\text { by harming their } \\
\text { image and self } \\
\text { worth and our } \\
\text { society prevents } \\
\text { men from } \\
\text { retaliating or } \\
\text { defending } \\
\text { themselves against } \\
\text { this." }\end{array}$ & $\begin{array}{l}\text { Social Isolation: } \\
\text { "My friends from } \\
\text { college, the few } \\
\text { who found out, } \\
\text { immediately } \\
\text { treated me like I } \\
\text { was Ted Bundy or } \\
\text { some other piece } \\
\text { of human trash } \\
\text { and cut ties." }\end{array}$ \\
\hline $\begin{array}{l}\text { Social } \\
\text { significance of } \\
\text { co-occurring } \\
\text { theme }\end{array}$ & $\begin{array}{l}\text { By highlighting } \\
\text { alcohol and consent } \\
\text { confusion, the } \\
\text { perpetrator } \\
\text { externalizes blame } \\
\text { and may be seeking } \\
\text { social approval }\end{array}$ & $\begin{array}{l}\text { Perpetrator } \\
\text { displays concern } \\
\text { for victim's } \\
\text { experience and } \\
\text { sets intention for } \\
\text { future pro-social } \\
\text { behavior }\end{array}$ & $\begin{array}{l}\text { Respondent's view } \\
\text { of himself is } \\
\text { affected by the } \\
\text { label "rape." He } \\
\text { reacts by } \\
\text { disparaging } \\
\text { women. }\end{array}$ & $\begin{array}{l}\text { Social isolation } \\
\text { that follows } \\
\text { perpetration leads } \\
\text { to suicidal } \\
\text { ideation. }\end{array}$ \\
\hline
\end{tabular}

Figure 1. The four primary outcomes of perpetrating sexual violence, the co-occurring themes, and the social significance of these themes. 
My friends from college, the few who found out, immediately treated me like I was Ted Bundy or some other piece of human trash and cut ties.

She told at least some of my friends and my roommate. He kicked me out, and I lost all my friends.
The only reason I haven't just done it, jumped off the Golden Gate Bridge or put my head in an exit bag, is because I know deep down my family still loves me.

Sometimes I wish I had never promised myself that I would never commit suicide
I found out she felt like I had raped her, I was so blown away by this I had no idea what to do. I was confused and hurt and just felt like shit.
I have never in my life felt as shitty and depressed as when she told me that she felt what happened was rape. The depression made me have to drop out of school and go live back home. My parents thought I was gonna try to kill myself so I started taking medication and going to

Figure 2. The relationship between social isolation, the label "rape," and depressed affect. 